Research Paper

\title{
Elephant grass leaves have lower recalcitrance to acid pretreatment than stems, with higher potential for ethanol production
}

\author{
Chayenne Correia Santos ${ }^{\mathrm{a}}$, Wanderley de Souza ${ }^{\mathrm{b}}$, Celso Sant 'Anna ${ }^{\mathrm{a}}$, Michel Brienzo ${ }^{\mathrm{c}, *}$

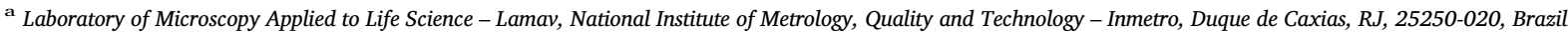 \\ b Laboratory of Cellular Ultrastructure Hertha Meyer, Federal University of Rio de Janeiro - UFRJ, Rio de Janeiro, RJ, 21949-900, Brazil \\ ${ }^{c}$ Bioenergy Research Institute (IPBEN), Universidade Estadual Paulista (UNESP), Rio Claro, SP, 13500-230, Brazil
}

\section{A R T I C L E I N F O}

\section{Keywords:}

Lignocellulosic

Elephant grass

Biomass fractions

Pretreatment

Enzymatic hydrolysis

Recalcitrance

\begin{abstract}
A B S T R A C T
Elephant grass is gaining attention among lignocellulosic materials due to its high growth potential, biomass yield, limited requirement for cultivation land and high rates of carbon dioxide absorption. Here was investigate the effect of pretreatment with different concentrations (5, 10 and 20\%, mass acid/mass material) of diluted sulfuric acid on the whole elephant grass plant compared with its leaf and stem fractions. The stem was the most recalcitrant fraction, judging from the high recovery of water insoluble solids (WIS) and lower enzymatic hydrolysis yield, upon acid pretreatment. In enzymatic hydrolysis assays, the glucose yield increased with increasing concentrations of acid, reaching maximum values of 89.20 (leaf), 43.54 (stem) and 76.01\% (whole plant). The crystallinity index (CrI) increased in both elephant grass fractions, which correlated with the solubilization of amorphous materials such as hemicellulose. Also, the stem fraction had a slightly higher heating value than the leaf fraction ( 3958.45 and $3939.49 \mathrm{cal} / \mathrm{g}$, respectively). Scanning electron microscopy (SEM) analysis showed drastic morphological changes in the samples with increasing pretreatment severity, although the stem fraction suffered less structural damage than other materials. Taken together, the results suggest that the separation of elephant grass in different fractions decreases biomass heterogeneity and generates a fraction (leaf) with lower inherent recalcitrance and, thus, higher susceptibility to pretreatment and enzymatic hydrolysis, increasing the efficiency of fermentable sugar release. The results indicate that the leaf fraction of elephant grass has higher potential for use in second-generation ethanol production, while the stem fraction may be more useful for energy co-generation by combustion.
\end{abstract}

\section{Introduction}

The increasing demand for energy, the depletion of oil reserves, and the need to preserve and protect the environment have stimulated large interest in alternative fuel sources, which can generate energy with low damage to the environment (Samson et al., 2005). In this context, lignocellulosic biomass emerges as an alternative feedstock resource for second-generation $(2 \mathrm{G})$ ethanol production, with economic and environmental advantages (Behera et al., 2014). In the last two decades, numerous studies have been carried out on ethanol production from lignocellulosic biomass (Joshi et al., 2011), which consists mainly of a network of the carbohydrates cellulose and hemicellulose, with 'gaps' filled in by the aromatic macromolecule lignin (Anwar et al., 2014).

Elephant grass (species Pennisetum purpureum) is a promising source of lignocellulosic biomass, and represents an alternative renewable material capable of efficient use of solar energy and biomass conversion, as a result of its potent photosynthetic metabolism (Flores et al., 2012a). The cultivation of elephant grass can yield stems with up to $3 \mathrm{~m}$ high, with annual production rates of $88 \mathrm{Mg}$ of dry matter per hectare (Pérez-Boada et al., 2014). Fontoura et al. (2015) demonstrated that it is economically feasible to use elephant grass as source of biomass for power plants in biorefinery systems (Fontoura et al., 2015).

Despite their potential industrial uses, lignocellulosic materials have inherent heterogeneity and 'recalcitrance' - the natural resistance of plant cell walls to degradation (Brethauer and Studer, 2015). To convert lignocellulosic materials into ethanol, a pretreatment approach is necessary to overcome biomass 'recalcitrance' and expose lignocellulosic carbohydrates for degradation, by disrupting the cell wall structure and making cellulose more accessible to cellulolytic enzymes that convert carbohydrates into fermentable sugars (Alvira et al., 2010). Several pretreatments techniques (dilute acid and alkaline) are under investigation to improve the digestibility of different biomass sources (Camesasca et al., 2015).

To overcome recalcitrance, a dilute acid pretreatment has been

\footnotetext{
* Corresponding author.

E-mail address: mbrienzo@ipben.unesp.br (M. Brienzo).
} 
widely applied which effectively depolymerizes hemicellulose, with limited generation of toxic degradation products (Alvira et al., 2010). The digestibility of dilute acid-pretreated materials correlates well with the decrease in the hemicellulose fraction, which indicates better enzymatic hydrolysis yield (Öhgren et al., 2007). Moreover, acid pretreatment effectively modifies/disrupts the lignin structure, making cellulose more accessible to enzymatic hydrolysis (Alvira et al., 2010; Brethauer and Studer, 2015).

The macromolecular composition and structural organization differ between plant regions, which generates heterogeneity in lignocellulosic material (Brienzo et al., 2014). The recalcitrant and heterogeneous lignocellulosic biomass responds differently to pretreatments, depending on its chemical and structural properties (Brienzo et al., 2015), and on the plant fractions from which it is originated (Brienzo et al., 2014). This implies that an understanding of the structural properties (such as heterogeneity and morphology) of lignocellulosic materials contributing to recalcitrance- is key to improve the fermentation yield of this promising alternative energy source (Sant'Anna et al., 2014).

The composition, lignin distribution and cell wall thickness in different biomass fractions affect the pretreatment and enzymatic hydrolysis efficiency. Ours and other groups have demonstrated the effect of plant biomass heterogeneity on the recalcitrance of important crops such as sugarcane and corn (Brienzo et al., 2014; Zeng et al., 2012). Sugarcane external fractions, internode and node showed different recalcitrance to acid, alkaline and peroxide pretreatment (Brienzo et al., 2017). On the other hand, Zeng et al. (2012) showed that the corn rind fraction has lower recalcitrance compared with the pith fraction (Zeng et al., 2012).

In this study, it was examined the recalcitrance of different fractions of elephant grass, an industrial crop whose recalcitrance had only been examined previously as a whole plant biomass (Cardona et al., 2014; Menegol et al., 2014). It was examined the heterogeneity of elephant grass after pretreatment with acid, which is widely used and has limited toxic waste generation. A detailed analysis of the individual responses of the leaf and stem fractions of elephant grass to diluted sulfuric acid pretreatment, in comparison with the whole plant was performed. Sugar solubilization, water-insoluble solids (WIS) recovery, crystallinity index and enzymatic hydrolysis of untreated and pretreated materials were performed, and measured the combustion heat of each fraction by calorimetry. Also, scanning electron microscopy (SEM) was used to investigate the changes in fraction surface morphology induced by acid pretreatment.

\section{Material and methods}

\subsection{Biomass}

Elephant grass from the species Pennisetum purpureum was cultivated for 6 months in an Experimental Field at Embrapa Agrobiology (Rio de Janeiro, Brazil). The elephant grass (10 plants) was used as whole plant samples (including leaf and stem), or separated into leaf and stem fractions. To remove free sugars and extractives, all samples were cut into small pieces of $\sim 5 \mathrm{~mm}$, or milled and selected with a 20 mesh sieve, washed in $95 \%$ ethanol for $48 \mathrm{~h}$ and then washed in distilled water for a further $48 \mathrm{~h}$, using a Soxhlet extractor system. Samples were dried in an oven at $45^{\circ} \mathrm{C}$ for $24 \mathrm{~h}$, and then stored in plastic bottles (at room temperature).

\subsection{Sulfuric acid pretreatment}

Elephant grass samples (whole plant, and leaf and stem fractions) were left untreated or pretreated with sulfuric acid at 5, 10 or $20 \%$ (mass acid/mass material; $\mathrm{m} / \mathrm{m}$ ) in $100 \mathrm{~mL}$ glass bottles, by addition of $60 \mathrm{~mL}$ sulfuric acid solutions to $3 \mathrm{~g}$ of sample (dry material). Pretreatments were performed in an autoclave, at $121^{\circ} \mathrm{C}$, for $30 \mathrm{~min}$. After pretreatment, samples were submerged in a cold-water bath, the slurry was vacuum-filtered, using filter paper, into solid and liquid fractions, and the resulting pretreated solid fraction was washed with distilled water (to neutralize the $\mathrm{pH}$ ) and dried at $45^{\circ} \mathrm{C}$, for $48 \mathrm{~h}$. Solid fractions were weighed and stored in plastic bottles (at room temperature) until further use, while liquid fractions were filtered using $0.22 \mu \mathrm{m}$ filters, prior to use in chemical composition analysis.

\subsection{Chemical composition analysis}

The chemical composition of samples was determined according to the National Renewable Energy Laboratory Analytical Procedures (NREL, USA) (Sluiter et al., 2010). The concentration of monomeric sugars (glucose, xylose and arabinose) in liquid fractions of pretreated samples was analyzed using a high-performance liquid chromatography system (HPLC; Shimadzu Corporation, Japan) equipped with a BIORAD HPX87H column and an RID 10A refractive index detector (Shimadzu). The analysis was performed at $60{ }^{\circ} \mathrm{C}$ using $5 \mathrm{mM}$ sulfuric acid as a mobile phase, with a flow rate of $0.6 \mathrm{~mL} / \mathrm{min}$ and a run-time of $25 \mathrm{~min}$. The following factors were used to convert sugar monomers into anhydromonomers: 0.90 for glucose, 0.88 for xylose and arabinose, and 0.72 for acetyl content. The concentration of each sugar fraction was expressed as the percentage of glucan (anhydroglucose), and 'Total hemicellulose' collectively referred to anhydromonomers of xylose, arabinose and acetic acid. The removal of hemicellulose was calculated relative to its content $(\mathrm{g} / \mathrm{g})$ in the untreated and pretreated samples. The initial biomass for the pretreatment was $3 \mathrm{~g}$ per sample, and after pretreatment a solid fraction was recovered (water-insoluble solids, WIS).

\subsection{Crystallinity index of the biomass}

The crystallinity of solid fractions of untreated and pretreated samples was analyzed using an X-ray diffractometer (SuperNova; Oxford Difraction Poland, Wroclaw, Poland) with a Cu tube at an accelerating voltage of $40 \mathrm{kV}$ and a current of $30 \mathrm{~mA}$. Scans were conducted at a $2 \theta$ angle, between 8 and $28^{\circ}$, with a step of $0.05^{\circ}$, and at a scan rate of $2^{\circ} / \mathrm{min}$. The crystallinity index ( $\left.\mathrm{CrI}\right)$ was calculated as the percentage of crystalline material, using the equation 1 :

CrI $(\%)=100 *\left(\mathrm{I}_{002}-\mathrm{I}_{001}\right) / \mathrm{I}_{002}$

where $\mathrm{CrI}$ is the relative degree of crystallinity, $\mathrm{I}_{002}$ is the intensity of the diffraction from the 002 plane at $2 \theta=22^{\circ}$, and $I_{001}$ is the peak intensity of the amorphous zone at $2 \theta=16^{\circ}$, in diffractograms.

\subsection{Enzymatic hydrolysis}

Enzymatic hydrolysis was performed with untreated and acid pretreated samples, by incubating $0.1 \mathrm{~g}$ of samples in $5 \mathrm{~mL}$ of $0.05 \mathrm{M}$ citrate buffer ( $\mathrm{pH} 4.8$ ), in $15 \mathrm{~mL}$ flasks, at $50{ }^{\circ} \mathrm{C}$, and with constant agitation (in an orbital shaker, at $170 \mathrm{rpm}$ ). Reactions mixtures contained $15 \mathrm{FPU} / \mathrm{g}$ cellulose (Celluclast $1.5 \mathrm{~L}$, Novozymes) and $15 \mathrm{U} / \mathrm{g}$ cellobiase ( $\beta$-glucosidase, Novozyme 188), to ensure activity and prevent product inhibition, respectively. The enzymatic digestibility of cellulose was calculated from the glucose yield (measured by HPLC as described in the item 2.3) after different reaction times (2, 4, 6, 8, 16, 24 and $48 \mathrm{~h}$ ). Enzymatic hydrolysis assays were performed in experimental duplicates, and averaged results were reported here. The glucan conversion was calculated according to Eq. (2):

Glucan conversion

$(\%)=100 *($ Glucose $+1.053 \times$ Cellobiose $) /$

$(1.11 \times \mathrm{f} \times$ Biomass $)$

Where: 
[Glucose] Concentration of glucose released during enzymatic hydrolysis $(\mathrm{g} / \mathrm{L})$

[Cellobiose] Concentration of cellobiose released during enzymatic hydrolysis $(\mathrm{g} / \mathrm{L})$

[Biomass] Dry biomass concentration at the beginning of the enzymatic hydrolysis $(\mathrm{g} / \mathrm{L})$

f Glucan fraction in dry biomass $(\mathrm{g} / \mathrm{g})$

1.053 Correction factor of cellobiose to glucose equivalents

1.111 Conversion factor of glucan to glucose equivalents

\subsection{Heating value}

Thermal Degradation (TD) (heating value) was performed in a Calorimeter (Parr Instrument Company, Parr 6400 Calorimeter, Illinois, USA) by burning $300 \mathrm{mg}$ of untreated samples, as well as commercial cellulose and lignin (Sigma Aldrich). The higher heating value is defined as the amount of heat released by a specified quantity of mass (initially at $25^{\circ} \mathrm{C}$ ) once it is combusted and the products have returned to a temperature of $25{ }^{\circ} \mathrm{C}$, which takes into account the latent heat of vaporization of water in the combustion products.

\subsection{Scanning electron microscopy (SEM)}

For scanning electron microscopy analysis, untreated and acid pretreated fractions (leaf and stem) were cut into small pieces $\left(5 \times 5 \mathrm{~mm}\right.$ ), washed with deionized water and dried at $45{ }^{\circ} \mathrm{C}$ for $24 \mathrm{~h}$. Samples were mounted onto stubs using carbon double-sided tape and examined in a FEI Quanta FEG 450 scanning electron microscope, operating at an accelerating voltage of $1 \mathrm{kV}$.

\section{Results and discussion}

\subsection{Chemical composition of elephant grass fraction}

Acid pretreatment is commonly used for hemicellulose solubilization, improving biomass digestibility. Despite the potential of elephant grass for the use as source for ethanol production, the effectiveness of acid pretreatment of different parts of the plant had not been examined previously. Relatively high concentrations of acid were used to allow us to pretreat samples at a low temperature (Brienzo et al., 2014).

Chemical characterization is the first step in the establishment of energy conversion processes, as it allows the detection of raw material variability, processes of optimization and the establishment of quality parameters (Chies, 2013). In untreated elephant grass samples (i.e., not subjected to acid pretreatment) was observed small differences only in the chemical composition (cellulose/glucan, total hemicelluloses and lignin) between the whole plant and the leaf and stem fractions (Table 1). There were no significant differences in the values of extractives for the whole plant $(26.04 \%)$ when compared with leaf (25.25\%) and stem $(25.38 \%)$.

The chemical composition data described in this study corroborated previous studies that reported values of $30-37 \%$ cellulose, $20-31 \%$ hemicellulose, and $8-21 \%$ lignin for elephant grass samples (Sladden et al., 1991; Santos et al., 2001; Menegol et al., 2014). The variations observed between studies may be explained by differences in environmental factors - including climatic changes (temperature and humidity), land constitution, infections and pests, planting methods, harvest seasons, among others - which affect the chemical composition of plants, leading to variation between plants of the same species (Menardo et al., 2013).

The breakdown of cellulose into glucose is fundamental for $2 \mathrm{G}$ ethanol production, irrespective of the cellulose content of biomass samples. Elephant grass has high cellulose content, which makes this biomass source particularly attractive from the perspective of fermentable sugar production, and consequently ethanol production (Phitsuwan et al., 2016). In addition, the lower lignin content found in elephant grass compared with other lignocellulosic materials likely results in a lower inherent recalcitrance, and hence facilitates cell wall disruption and the efficient release of fermentable monomeric sugars (Brienzo et al., 2017; Wallace et al., 2016).

\subsection{Acid pretreatment increases the recovery of water insoluble solids}

Pretreatments usually result in a considerable mass loss of plant biomass components, depending on the pretreatment method, the experimental conditions, and the biomass used for conversion (Chatuvedi and Verma, 2013). In the more recalcitrant plant fractions mass recovery after acid pretreatment is high and, thus, lower sugar concentrations are found in liquid fractions (Brodeur et al., 2011). In this work, the solid recovery (water insoluble solids - WIS) from samples pretreated with sulfuric acid varied from $54.36 \%$ to $66.37 \%$, with $5 \%$ sulfuric acid yielding higher solid recovery than other pretreatments, followed by $10 \%$ and $20 \%$ sulfuric acid pretreatments (Table 1 ). The stem fractions showed higher resistance to mass loss (i.e., higher solid recovery) upon pretreatment than leaf and dried whole plant samples (Table 1), indicating reduced solubilization of compounds such as hemicellulose sugars. The decrease in solid recovery observed in this work in the samples pretreated with acid (particularly the leaf and whole plant samples) was likely due both to the solubilization of carbohydrates (mainly hemicellulose) and to the partial removal of lignin

Table 1

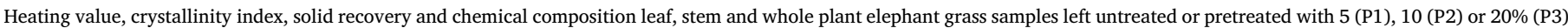
of sulfuric acid $\left(5,10\right.$ and $20 \% \mathrm{~m} / \mathrm{m}$ acid at $121{ }^{\circ} \mathrm{C} / 30 \mathrm{~min}$ ).

\begin{tabular}{|c|c|c|c|c|c|c|}
\hline \multirow[t]{2}{*}{ Sample } & \multicolumn{3}{|c|}{ Chemical composition (\%, dry mass) } & \multirow[b]{2}{*}{ Solid recovery } & \multirow[b]{2}{*}{ Heating value $\left(\mathrm{cal} \mathrm{g}^{-1}\right)$} & \multirow[b]{2}{*}{ CrI (\%) } \\
\hline & Glucan & Hemicellulose total & Lignin total & & & \\
\hline Leaf & $32.28 \pm 0.38$ & $22.41 \pm 0.94$ & $14.37 \pm 0.51$ & - & $3939.49 \pm 6.19$ & $35.13 \pm 5.40$ \\
\hline Stem & $34.10 \pm 2.39$ & $24.94 \pm 2.54$ & $15.49 \pm 1.29$ & - & $3958.45 \pm 9.40$ & $40.32 \pm 1.45$ \\
\hline E.grass & $33.85 \pm 0.75$ & $23.93 \pm 1.75$ & $14.15 \pm 0.74$ & - & - & $37.06 \pm 1.45$ \\
\hline Leaf - P1 & $41.34 \pm 1.68$ & $14.22 \pm 1.92(63.36)$ & $14.87 \pm 1.81$ & $59.12 \pm 2.78$ & - & $49.03 \pm 1.57$ \\
\hline Leaf - P2 & $40.15 \pm 1.55$ & $11.47 \pm 1.70(75.70)$ & $26.97 \pm 2.32$ & $55.86 \pm 0.43$ & - & $54.20 \pm 1.41$ \\
\hline Leaf - P3 & $42.70 \pm 1.62$ & $9.40 \pm 0.25(85.02)$ & $27.21 \pm 3.74$ & $54.56 \pm 0.68$ & - & $55.89 \pm 4.94$ \\
\hline Stem - P1 & $43.72 \pm 2.66$ & $16.39 \pm 2.18(62.63)$ & $19.45 \pm 2.45$ & $66.37 \pm 3.36$ & - & $52.69 \pm 3.19$ \\
\hline Stem - P2 & $44.60 \pm 2.89$ & $13.97 \pm 0.71(74.03)$ & $21.02 \pm 2.95$ & $60.28 \pm 0.56$ & - & $55.53 \pm 4.94$ \\
\hline Stem - P3 & $48.87 \pm 2.48$ & $12.86 \pm 2.86(76.71)$ & $27.46 \pm 3.09$ & $58.34 \pm 0.76$ & - & $52.15 \pm 0.40$ \\
\hline E.grass - P1 & $36.89 \pm 0.87$ & $15.64 \pm 0.26(60.96)$ & $16.56 \pm 5.50$ & $59.90 \pm 0.94$ & - & $42.14 \pm 0.42$ \\
\hline E.grass - P2 & $38.28 \pm 2.69$ & $10.80 \pm 1.54(77.02)$ & $22.11 \pm 1.89$ & $54.96 \pm 1.72$ & - & $47.96 \pm 3.36$ \\
\hline E.grass - P3 & $43.13 \pm 2.21$ & $10.72 \pm 1.14(74.94)$ & $23.32 \pm 4.62$ & $54.36 \pm 0.42$ & - & $49.51 \pm 1.75$ \\
\hline
\end{tabular}

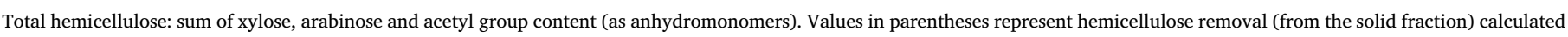

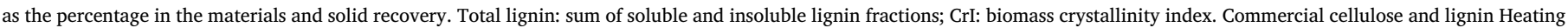
value were $3837.42 \pm 11.34$ and $4657.25 \pm 9.56 \mathrm{cal} \mathrm{g}^{-1}$. (-) not determined. 
(Scholl et al., 2015).

The percentage of cellulose and lignin increased in all acid-pretreated samples, when compared with untreated materials (Table 1), which was likely due to the solubilization and removal of the hemicellulosic fraction. Treatment of the stem fraction led to the highest cellulose/glucan percentage compared with other fractions (from $43.72 \%$ to $48.87 \%$ after exposure to sulfuric acid; Table 1 ). The reduction in hemicellulose content after pretreatment was due to its relatively amorphous nature, large polidispersity and lower degree of polymerization when compared with native cellulose, making hemicellulose more susceptible to removal/solubilization during acid pretreatment (Bottcher et al., 2013). Among the main biomass components, hemicellulose is removed preferentially after acid pretreatment (Brienzo et al., 2017). The removal of hemicellulose was higher from the leaf fraction $(85.02 \%)$ than from the stem fraction $(76.71 \%)$ and from the whole plant (74.94\%) (Table 1). The leaf and whole plant samples analyzed in this study had lower lignin content than stem samples, suggesting that the latter were more recalcitrant, since the lignin content is directly linked to the difficulty in disrupting plant cell walls (Jia et al., 2014). In general, leaf samples were more sensitive to acid pretreatment than stem and whole plant samples, as could be observed a higher hemicellulose solubilization. The extension of carbohydrates solubilization probably is not related to the amount of sugars (hemicellulose) or lignin since they are similar (Table 1). Moreover, there are physicochemical properties of the biomass that could have influence in the leaf and stem recalcitrance: accessibility and porosity (Brienzo et al., 2015), lignin distribution (Brienzo et al., 2017). Also, it is clear that a leaf structure result in lower density, influencing the accessibility, compared to a stem.

\subsection{Acid pretreatment increases the crystallinity of elephant grass fractions}

The crystallinity index (CrI) of lignocellulosic materials is directly influenced by the amount of crystalline cellulose regions within native cellulose (Sant'Anna et al., 2014). Importantly, crystallinity is a key property that affects the enzymatic digestibility of cellulose, with high crystallinity decreasing digestibility ( $\mathrm{Rg}$ et al., 2012). Acid pretreatment results in the solubilization of sugars, especially amorphous hemicellulose components, increasing the proportion of crystalline components (such as cellulose), which become considerably enriched in the biomass after acid treatment (Corrales et al., 2012). Thus, early studies revealed an increase in the CrI after pretreatment, due to amorphous fraction removal (Corrales et al., 2012; Brienzo et al., 2014).

An increase in the CrI of acid pretreated samples was observed, in relation to untreated materials, for whole plant, leaf and stem samples (Table 1). Also, the stem had higher CrI than both the whole plant and the leaf fraction (Table 1). The crystallinity values reported here were lower than those previously reported by Satyanarayana and Wypych (2007) for elephant grass plant, and by Corrales et al. (2012) for sugarcane bagasse (47 and 48\%, respectively, compared with $35.13-40.32 \%$ observed here; Table 1 ). It is possible that the amount of extractives (around 25\%) of the samples analyzed here contributed to the observed decrease in the CrI index.

The results indicated that increasing concentrations of acid in the pretreatment led to increased removal of hemicellulose (Table 1). Accordingly, pretreatment with increasing concentrations of acid led to a gradual increase in the CrI, for leaf and whole plant samples. The stem fraction was more resistant to pretreatment than the leaf fraction and the whole plant, as evidenced by the lower sugar solubilization. Moreover, the increase in the CrI value after pretreatment with $20 \%$ sulfuric acid (relative to the untreated) was higher for the leaf fraction (by 20.76 percentage points, pp) than for the whole plant (by $12.45 \mathrm{pp}$ ) and the stem fraction (by $11.83 \mathrm{pp}$ ) (Table 1 ).

\subsection{Both stem and leaf fractions of elephant grass have high heating value}

The heating value analysis measures the capacity of fuel energy generation during combustion, in $\mathrm{kcal} \mathrm{g}^{-1}$ or cal $\mathrm{g}^{-1}$ of biomass (Flores et al., 2012b). The heating value was similar for the stem $\left(3958.45 \mathrm{cal} \mathrm{g}^{-1}\right.$ ) and leaf fraction (3939.49 cal g${ }^{-1}$ ) (Table 1). Nevertheless, the heating values for both fractions are considered high (Sheng and Azevedo, 2005), suggesting that these fractions are suitable for combustion processes. As a comparison, the commercial cellulose and lignin heating values were 3837.42 and $4657.25 \mathrm{cal} \mathrm{g}^{-1}$, respectively (Table 1 ). This result confirms the influence of the chemical composition on the combustion of lignocellulosic material, as reported previously (Demirbas, 2002). An average heating value of $4096 \mathrm{cal} \mathrm{g}^{-1}$ was reported previously for elephant grass stem and leaf (Flores et al., 2012b), while the heating values reported for to whole plant were $3501 \mathrm{cal} \mathrm{g}^{-1}$ (Onuegbu et al., 2012) and $4337 \mathrm{cal} \mathrm{g}^{-1}$ (Rocha et al., 2017). The elephant grass heating value is close to that of other lignocellulosic materials such as Eucalyptus (4507 cal $\mathrm{g}^{-1}$ ) (Munalula and Meincken, 2009), and sucrose-free sugarcane fractions (from 3998 to $4236 \mathrm{cal} \mathrm{g}^{-1}$ ) (Brienzo et al., 2014).

For $2 \mathrm{G}$ ethanol production, the selection of varieties with high lignin content is unfavorable due to their high recalcitrance (Benjamin et al., 2013). Similarly, varieties with high recalcitrance are also negative to the conversion process (Brienzo et al., 2015). However, the high heating value of elephant grass favors its use for the generation of thermal and electric energy. Moreover, the higher recalcitrance of the steam, compared to leaf, suggest to be appropriate to use this fraction in the energy co-generation. This energy could supply, for example, part of the heat demand for the transformation of lignocellulosic residues into fuels (Haykiri-Acma et al., 2010).

\subsection{The stem fraction of elephant grass has higher recalcitrance to enzymatic hydrolysis}

An enzymatic hydrolysis assay was used to investigate the effect of diluted sulfuric acid pretreatment on the recalcitrance of elephant grass plant and its fractions (Fig. 1A-C). Untreated lignocellulosic material typically shows low glucose yield of around 20\% (Corrales et al., 2012; Brienzo et al., 2014), due to its intrinsic resistance to enzymatic action (Wang et al., 2009; Brienzo et al., 2015). In this study, the conversion of cellulose into glucose in untreated whole plant, stem or leaf samples was similar, around $20 \%$ (Fig. 1). These results suggested that the elephant grass plant and its fractions are recalcitrant, which highlights the need for a pretreatment to overcome this natural resistance to digestion (Sant'Anna et al., 2014).

Indeed, the glucose yield increased in the pretreated samples compared with the untreated ones (Fig. 1). A pretreatment with $5 \%$ acid provoked modification in the material digestibility increasing the glucose release compared to untreated material. It was evidenced the lower recalcitrance of the leaf, with higher glucose yield than steam, probably due the physicochemical properties and also lower lignin content (Table 1). The highest glucose yield was obtained in the leaf fraction (89\%), followed by the whole plant $(76 \%)$, and then by the stem fraction (43\%), after pretreatment with $20 \%$ sulfuric acid (Fig. 1). Pérez-Boada et al. (2014) reported that the response to enzymatic hydrolysis differs between ball-milled elephant grass pith (50\%), outer cortex (31\%) and whole stem (35\%). The enzymatic kinetics was similar for stem, leaf and whole plant samples subjected to pretreatments with 10 and $20 \%$ sulfuric acid (Fig. 1). However, pretreatments with $5 \%$ sulfuric acid led to reduced glucose yields (Fig. 1).

These enzymatic hydrolysis results also indicated that $10 \mathrm{~h}$ (for stem) and $24 \mathrm{~h}$ (for leaf and whole plant) are a reliable time to perform the hydrolysis of pretreated material, because there were no relative increase in the glucose yield at longer hydrolysis times (Fig. 1). For leaf, there is an intermediate phase between 10 and $24 \mathrm{~h}$, where after reaching a recalcitrance phase, resulting in low glucose yield increases. 


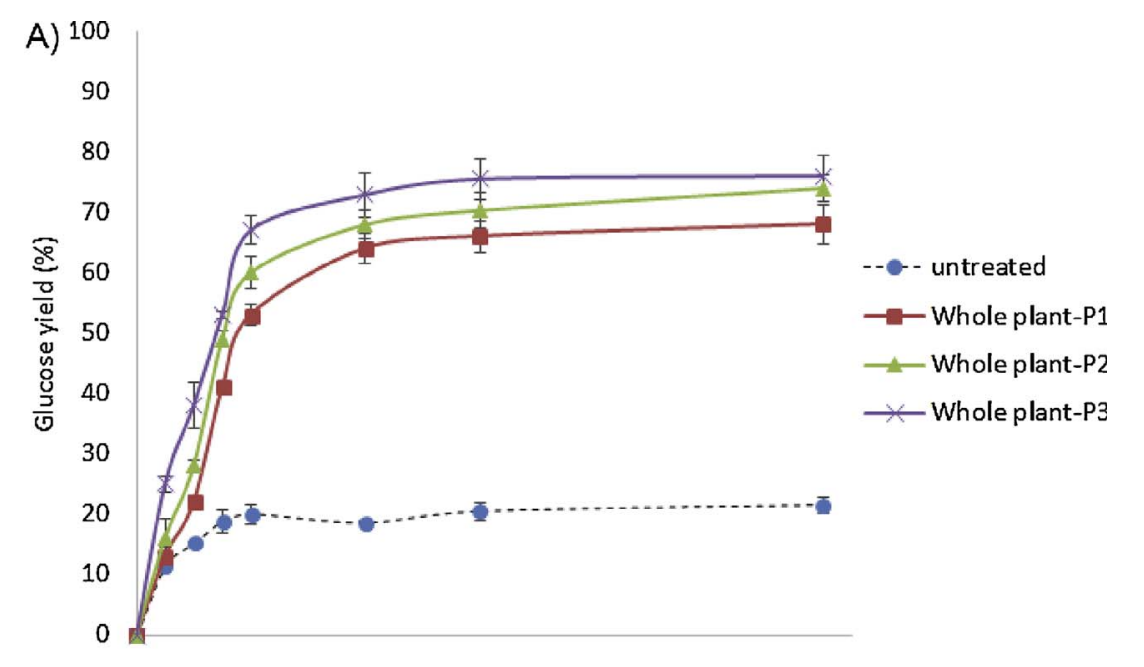

Fig. 1. Glucose yield from enzymatic hydrolysis (using $15 \mathrm{FPU} / \mathrm{g}$ and $15 \mathrm{U} / \mathrm{g} \beta$-glucosidase) of whole plant (A), leaf (B) and stem (C) fractions of elephant grass left untreated or pretreated with 5 P1), 10 (P2) or $20 \%$ (P3) of sulfuric acid $\left(5,10\right.$ and $20 \% \mathrm{~m} / \mathrm{m}$, at $121{ }^{\circ} \mathrm{C}$, for $30 \mathrm{~min})$.

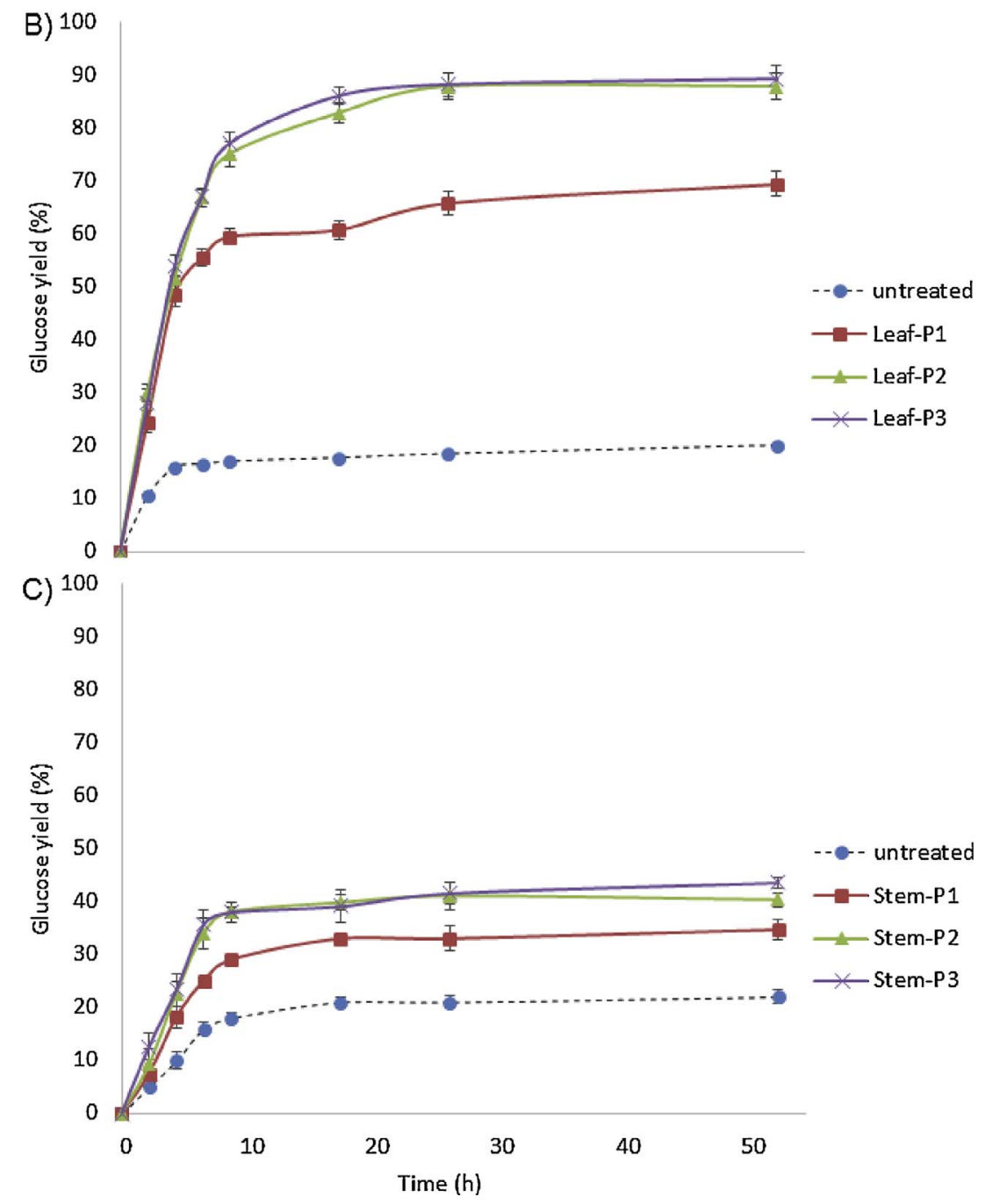

During the enzymatic hydrolysis occurs a process slowdown due to cellulose removal and lignin enrichment, which protecs cellulose from enzyme action (Wallace et al., 2016). Elephant grass pretreated with other methods, such as steam explosion and aqueous ammonia soaking, had similar enzymatic hydrolysis kinetics to those reported here, with high glucose yields after $24 \mathrm{~h}$ of reaction (Cardona et al., 2014). In contrast, higher yields have been reported using surfactants such as Tween 80, but only after $48 \mathrm{~h}$ of reaction (Menegol et al., 2014).

The higher lignin content of the stem fraction is likely to contribute

to its higher recalcitrance (compared with the leaf fraction and the whole plant), with lower sensitivity to enzymatic hydrolysis and reduced glucose yield. Lignin forms a physical barrier to the access of enzymes to cellulose (Buranov and Mazza, 2008). The digestibility of the pretreated leaf fraction by enzymatic hydrolysis increased with increasing concentration of sulfuric acid in the pretreatment (Fig. 1). The acid concentration in the pretreatment led to an increase in the hemicellulosic solubilization (removing up to $85 \%$ of this fraction) with the most severe condition (Table 1). It is likely that acid pretreatment 
also triggered changes in the lignin structure of elephant grass samples, relocating it to the fiber surface, and, in turn, enhancing the yield in the enzymatic hydrolysis step (Domínguez et al., 2008).

Collectively, the data reported here indicate that pretreating the whole elephant grass plant implies in low efficiency of enzymatic hydrolysis, due to the inherent recalcitrance of each fraction that composes the biomass. The leaf fraction showed better results of cellulose conversion into glucose compared with the stem fraction and whole plant (Table 1). The data for the leaf and stem fractions clearly showed that separation of the biomass in more homogeneous fractions improves pretreatment efficacy and enzymatic hydrolysis. This approach favors the design of specific strategies for pretreating each fraction according to its recalcitrance (Sant'Anna et al., 2014). The fractionation of the elephant grass in this work resulted in similar kinetics of enzymatic hydrolysis to those reported for other acid-pretreated improved cultivars (Li et al., 2015).

The results suggested that a higher severity of diluted acid pretreatment should be applied to overcome the high degree of recalcitrance of the stem fraction. Considering the higher recalcitrance of this fraction, it seems that its resistance to digestion relies on the tissue organization, type of cells and/or cell wall structure. These features have been correlated with recalcitrance for other lignocellulosic materials, such as sugarcane bagasse (Sant'Anna et al., 2014; Brienzo et al., 2017).

\subsection{Acid pretreatment affected the surface morphology of elephant grass samples}

Scanning electron microscopy (SEM) images of untreated leaf and stem revealed a smooth cell wall surface without apparent damage (Figs. $2 \mathrm{~A}$ and $3 \mathrm{~A}$ ). Pretreatment with $5 \%$ sulfuric acid caused slight fiber disorganization in both leaf and stem fractions (Figs. 2 B and 3 B), and other morphological alterations were observed with increasing pretreatment severity (Figs. 2 and 3). Leaf samples subjected to $10 \%$ sulfuric acid pretreatment had a more disorganized and tumescent surface in comparison with untreated leaf (Fig. 2C). The highest concentration of sulfuric acid (20\%) strongly affected leaf surface morphology (Fig. 2D).

Lignin and their fragments migrate to the biomass surface during acid pretreatment, where they are deposited in the form of spheres (Moriya et al., 2007). Also, previous studies demonstrated the presence of pseudo-lignin - a structure composed of lignin and polysaccharide degradation products - deposited on the surface of lignocellulosic materials subjected to sulfuric acid pretreatment (Hu et al., 2012). SEM images of leaf pretreated with $20 \%$ sulfuric acid showed the expected modifications for its chemical composition, with the appearance of spherical structures resembling pseudo-lignin (Supplemental Fig. 1) deposited on the cell wall surface.

SEM images showed that the stem fraction suffered less structural damage after acid pretreatment, when compared with the leaf fraction. The higher structural disorganization observed in leaf pretreated with $20 \%$ sulfuric acid is in agreement with the higher hemicellulosic fraction removal (85.02\%) from this fraction, compared with that observed for other samples, and in other pretreatment conditions (Table 1). The stem fraction has different tissue/cell organization, with higher crystallinity, lignin content and probably higher density than the leaf (Table 1). These factors influence the physico-chemical properties of the material and, thus, its enzymatic digestibility (Brienzo et al., 2015). Moreover, the lignin content influences material recalcitrance, but this influence is highly dependent on the distribution and quantity of lignin in the tissue, and on the type of cells in the fraction (Bond et al., 2008; Sant'Anna et al., 2013; Brienzo et al., 2017). SEM images of the sulfuric acid pretreated leaf and stem fractions are in agreement with the positive effect of different sulfuric acid concentrations on the glucose yield
Untreated
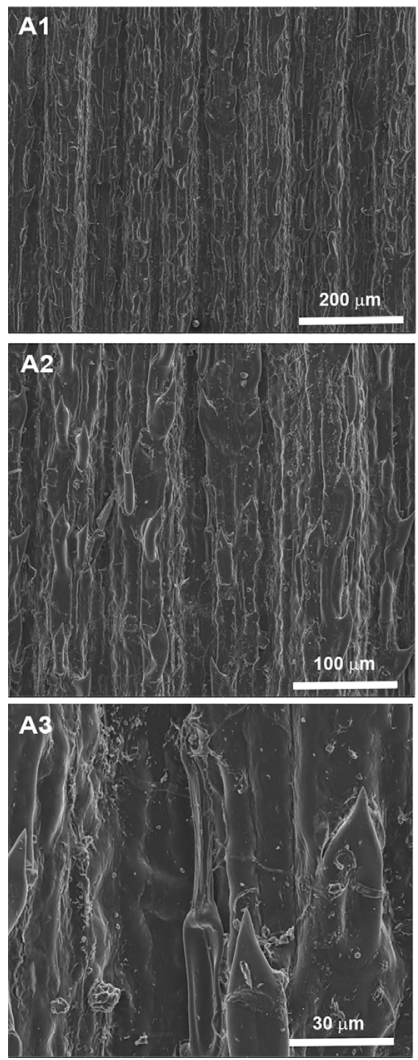

$5 \% \mathrm{H} 2 \mathrm{SO} 4$
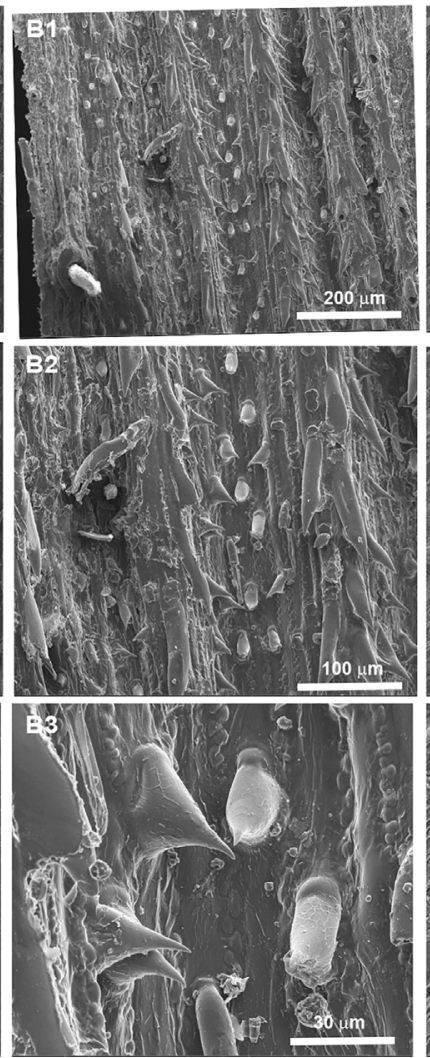

$10 \% \mathrm{H} 2 \mathrm{SO} 4$
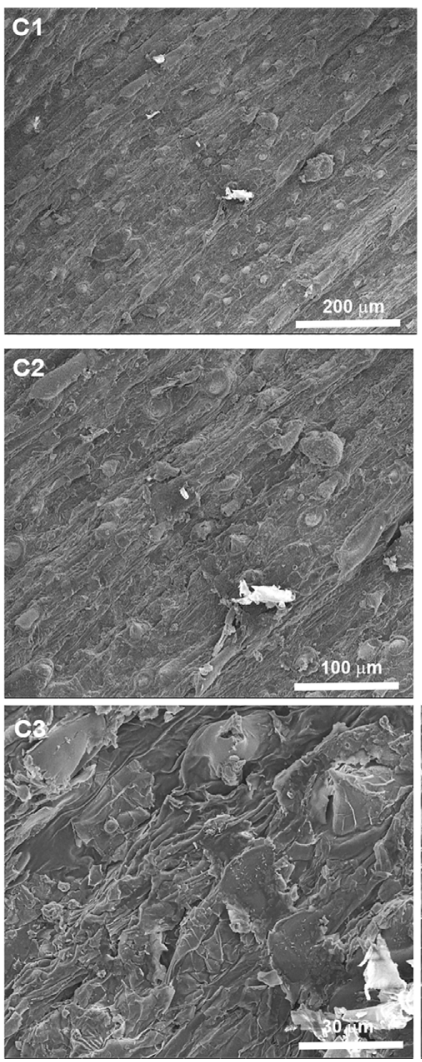

$20 \% \mathrm{H} 2 \mathrm{SO} 4$

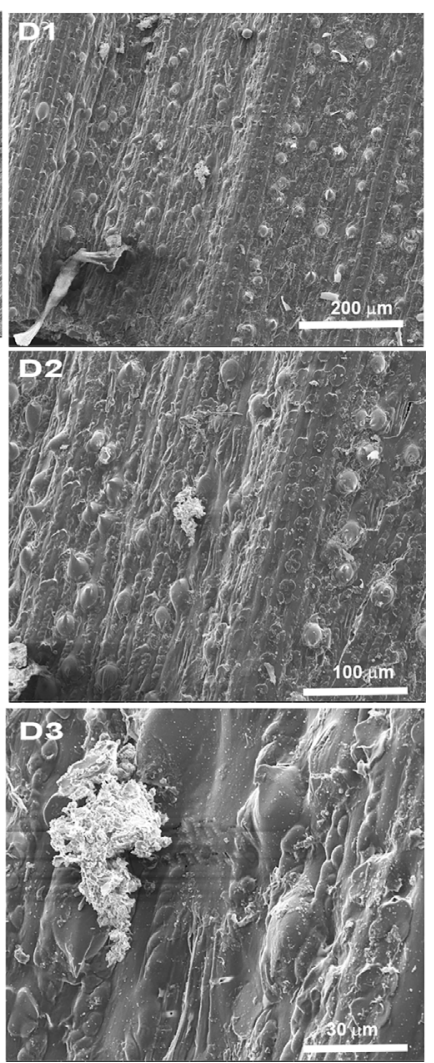

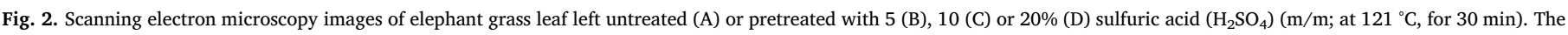
numbers 1-3 in panel names indicate images of the same area at increasing magnifications. 


\section{Untreated}
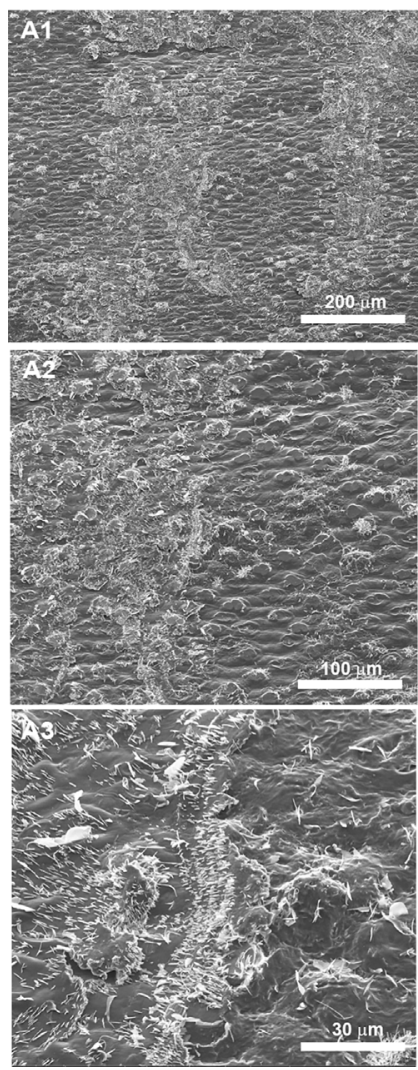

$5 \% \mathrm{H} 2 \mathrm{SO} 4$
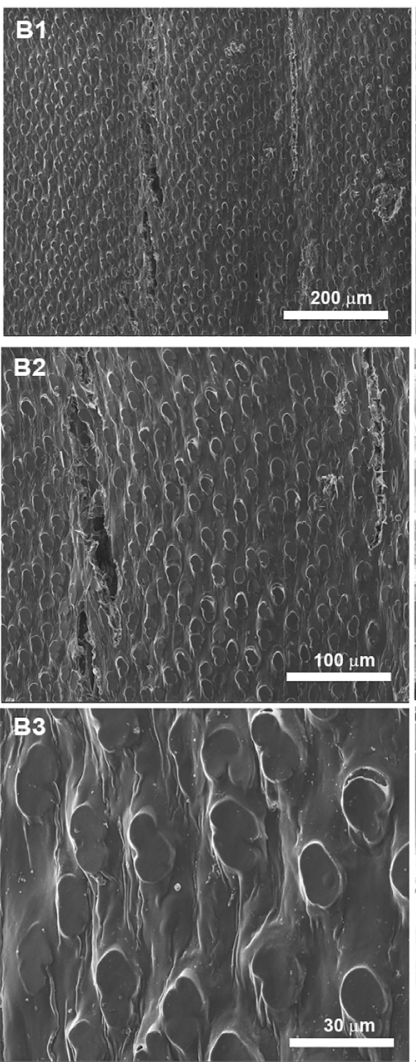

$10 \% \mathrm{H} 2 \mathrm{SO} 4$
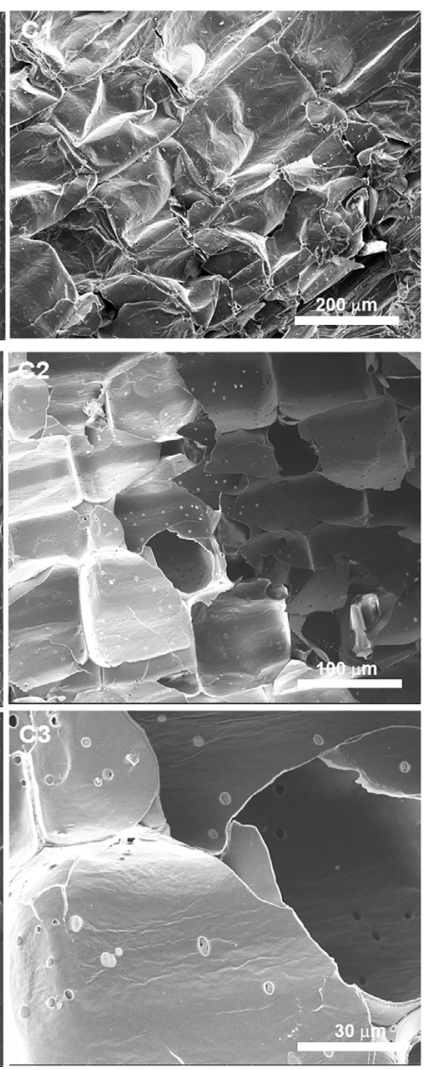

$20 \% \mathrm{H} 2 \mathrm{SO} 4$
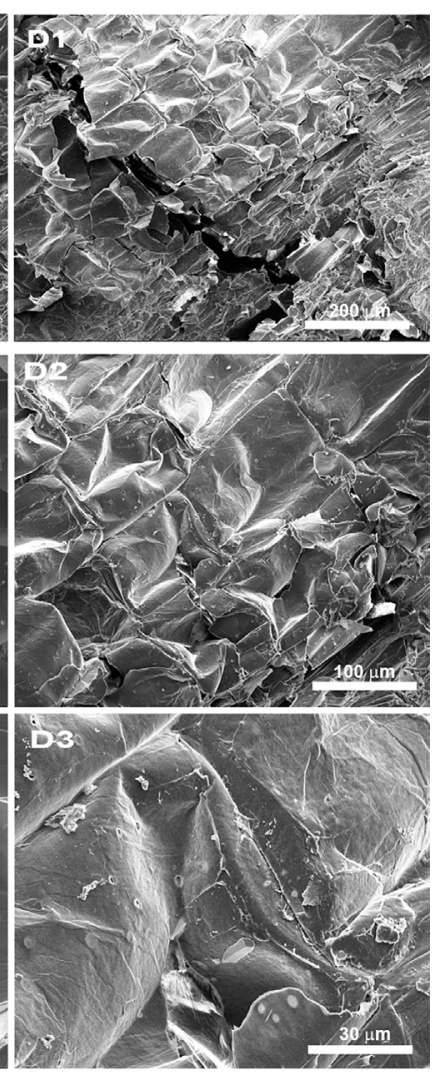

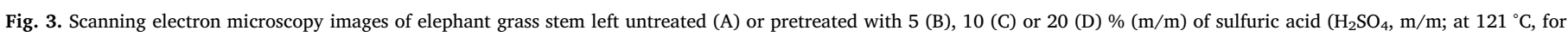
$30 \mathrm{~min}$ ). The numbers 1-3 in panel names indicate images of the same area at increasing magnifications.

by enzymatic hydrolysis (Fig. 1), showing that pretreatment increases the susceptibility of cellulose to enzyme action.

\section{Conclusion}

In this study, the potential of elephant grass fractions for ethanol production after acid pretreatment was examined. Acid pretreatment led to increased removal of solids and hemicellulose from elephant grass leaf fraction and whole plant, compared with the stem fraction. Hemicellulose removal was directly proportional to the acid concentration used in the pretreatment. The enzymatic hydrolysis yield after acid pretreatment was higher for the leaf fraction, followed by the whole plant, and the stem fraction. This effect is likely due to the complex stem organization, which is associated with higher lignin content, crystallinity and structural density. Overall, the analysis presented here highlighted the need to take into account the inherent recalcitrance of each plant fraction when evaluating pretreatment conditions, to ensure a high enzymatic hydrolysis yield for biofuel production. Moreover, the fractions could be used separately for different process: the stem, the most recalcitrant fraction, may be more useful for energy co-generation by combustion, while the leaf, which requires less severe pretreatment, is likely to be more useful in the $2 \mathrm{G}$ ethanol production.

\section{Acknowledgments}

The authors are thankful to the Brazilian Innovation Agency (FINEP), the Brazilian Council for Research and Development (CNPq), and National Institute of Metrology, Quality, and Technology (Prometro grant number 550105/2012-8) for financial support.

\section{Appendix A. Supplementary data}

Supplementary data associated with this article can be found, in the online version, at http://dx.doi.org/10.1016/j.indcrop.2017.10.013.

\section{References}

Alvira, P., Tomás-Pejó, E., Ballesteros, M., Negro, M., 2010. Pretreatment technologies for an efficient bioethanol production process based on enzymatic hydrolysis: a review. Bioresour. Technol. 13, 4851-4861.

Anwar, Z., Gulfraz, M., Irshad, M., 2014. Agro-industrial lignocellulosic biomass a key to unlock the future bio-energy: a brief review. J. Radiat. Res. Appl. Sci. 7, 163-173.

Behera, S., Arora, R., Nandhagopal, N., Kumar, S., 2014. Importance of chemical pretreatment for bioconversion of lignocellulosic biomass. Renew. Sustain. Energy Rev. 36, 91-106.

Benjamin, Y., Cheng, H., Görgens, J.F., 2013. Evaluation of bagasse from different varieties of sugarcane by dilute acid pretreatment and enzymatic hydrolysis. Ind. Crops Prod. 51, 7-18.

Bond, L., Donaldson, L., Hill, S., Hitchcock, K., 2008. Safranine fluorescent staining ofwood cell walls. Biotech. Histochem. 83, 161-171.

Bottcher, A., Cesarino, I., dos Santos, A.B., Vicentini, R., Mayer, J.L.S., Vanholme, R., Carmello-Guerreiro, S.M., 2013. Lignification in sugarcane: biochemical characterization, gene discovery, and expression analysis in two genotypes contrasting for lignin content. Plant Physiol. 163, 1539-1557.

Brethauer, S., Studer, M., 2015. Biochemical conversion processes of lignocellulosic biomass to fuels and chemicals-a review. Chimia 69, 572-581.

Brienzo, M., Ferreira, S., Vicentim, M.P., Souza, W., Sant'Anna, C., 2014. Comparison study on the biomass recalcitrance of different tissue fractions of sugarcane culm. Bioenergy Res. 7, 1454-1465.

Brienzo, M., Tyhoda, L., Benjamin, Y., Görgens, J., 2015. Relationship between physicochemical properties and enzymatic hydrolysis of sugarcane bagasse varieties for bioethanol production. New Biotechnol. 32, 253-262.

Brienzo, M., Fikizolo, S., Benjamin, Y., Tyhoda, L., Görgens, J., 2017. Influence of pretreatment severity on structural changes, lignin content and enzymatic hydrolysis of sugarcane bagasse samples. Renew. Energy 104, 271-280.

Brodeur, G., Yau, E., Badal, K., Collier, J., Ramachandran, K.B., Ramakrishnan, S., 2011. Chemical and physicochemical pretreatment of lignocellulosic biomass: a review. Enzym. Res 1-17.

Buranov, A.U., Mazza, G., 2008. Lignin in straw of herbaceous crops. Ind. Crops Prod. 28, 
237-259.

Camesasca, L., Ramírez, M., Guigou, M., Ferrari, M., Lareo, C., 2015. Evaluation of dilute acid and alkaline pretreatments: enzymatic hydrolysis and fermentation of napiergrass for fuel ethanol production. Biomass Bioenergy 74, 193-201.

Cardona, E., Rios, J., Peña, J., Rios, L., 2014. Effects of the pretreatment method on enzymatic hydrolysis and ethanol fermentability of the cellulosic fraction from elephant grass. Fuel 118, 41-47.

Chatuvedi, V., Verma, P., 2013. An overview of key pretreatment processes employed for bioconversion of lignocellulosic biomass into biofuels and value added products. Biotechnology 3, 415-431.

Chies, V., 2013. Pesquisa investe na caracterização de biomassa para obtenção de biocombustíveis. CONAB, Companhia Nacional de Abastecimento.

Corrales, R.C.N.R., Mendes, F.M.T., Perrone, C.C., Sant'Anna, C., de Souza, W., Abud, Y., Ferreira-Leitão, V., 2012. Structural evaluation of sugar cane bagasse steam pretreated in the presence of $\mathrm{CO} 2$ and SO2. Biotechnol. Biofuels 5, 36.

Demirbas, A., 2002. Relationships between heating value and lignin moisture, ash and extractive contents of biomass fuels. Energy Explor. Exploit. 20, 105-111.

Domínguez, J.C., Oliet, M., Alonso, M.V., Gilarranz, M.A., Rodríguez, F., 2008. Thermal stability and pyrolysis kinetics of organosolv lignins obtained from Eucalyptus globulus. Ind. Crops Prod. 27, 150-156.

Flores, A., Urquiaga, S., Alves, R., Collier, S., Boddey, M., 2012a. Yield and quality of elephant grass biomass produced in the cerrados region for bioenergy. Eng. Agric. 5,32 .

Flores, A.R., Urquiaga, S.S., Bruno, J.R.A., Collier, L.S., Morais, R.F., Prado, R.M., 2012b. Adubação nitrogenada e idade de corte na produção de matéria seca do capim-elefante no Cerrado. R. Bras. Eng. Agríc. Ambiental. 16, 1282-1288.

Fontoura, C.F., Brandão, L.E., Gomes, L.L., 2015. Elephant grass biorefineries: towards a cleaner Brazilian energy matrix. J. Clean Prod. 96, 85-93.

Haykiri-Acma, H., Yaman, S., Kucukbayrak, S., 2010. Comparison of the thermal reactivities of isolated lignin and holocellulose during pyrolysis. Fuel Process. Technol. 91, 759-764.

Hu, F., Jung, S., Ragauskas, A., 2012. Pseudo-lignin formation and its impact on enzymatic hydrolysis. Bioresour. Technol. 117, 7-12.

Jia, J., Yu, B., Wu, L., Wang, H., Wu, Z., Li, M., Peng, L., 2014. Biomass enzymatic saccharification is determined by the non- $\mathrm{KOH}$-extractable wall polymer features that predominately affect cellulose crystallinity in corn. Plos One 9.

Joshi, B., Bhatt, M.R., Sharma, D., Joshi, J., Malla, R., Sreema, L., 2011. Lignocellulosic ethanol production: current practices and recent developments. Biotechnol. Mol. Bio. Rev. 6, 172-182.

Li, Y., Zhang, Y., Zheng, H., Du, J., Zhang, H., Wu, J., Huang, H., 2015. Preliminary evaluation of five elephant grass cultivars harvested at different time for sugar production. Chin. J. Chem. Eng. 23, 1188-1193.

Menardo, S., Bauer, A., Theuretzbacher, F., Piringer, G., Nilsen, P., Balsari, P., Pavliska, O., Amon, T., 2013. Biogas production from steam-exploded Miscanthus and utilization of biogas energy and $\mathrm{CO}_{2}$ in greenhouses. BioEnergy Res. 6, 620-630.

Menegol, D., Scholl, A.L., Fontana, R.C., Dillon, A.J.P., Camassola, M., 2014. Potential of a Penicillium echinulatum enzymatic complex produced in either submerged or solidstate cultures for enzymatic hydrolysis of elephant grass. Fuel 133, 232-240.

Moriya, R.Y., Gonçalves, A.R., Duarte, M.C., 2007. Ethanol/water pulps from sugar cane straw and their biobleaching with xylanase from Bacillus pumilus. Appl. Biochem. Biotecnol. 137-140, 501-513.

Munalula, F., Meincken, M., 2009. An evaluation of South African fuelwood withregards to calorific value and environmental impact. Biomass Bioenergy 33, 415-420.
Öhgren, K., Bura, R., Saddler, J., Zacchi, G., 2007. Effect of hemicellulose and lignin removal on enzymatic hydrolysis of steam pretreated corn stover. Bioresour. Technol. 98, 2503-2510.

Onuegbu, T.U., Ogbu, I.M., Ejikeme, C., 2012. Comparative analyses of densities and calorific values of wood and briquettes samples prepared at moderate pressure and ambient temperature. IJPAES 2, 40-45.

Pérez-Boada, M., Prieto, A., Prinsen, P., Forquin-Gomez, M.-P., del Río, J.C., Gutiérrez, A., Martínez, A.T., Faulds, C.B., 2014. Enzymatic degradation of Elephant grass (Pennisetum purpureum) stems: influence of the pith and bark in the total hydrolysis. Bioresour. Technol. 167, 469-475.

Phitsuwan, P., Sakka, K., Ratanakhanokchai, K., 2016. Structural changes and enzymatic response of Napier grass (Pennisetum purpureum) stem induced by alkaline pretreatment. Bioresour. Technol. 218, 247-256.

Rg, C., Godoy, G.G., Gonçalves, A.R., 2012. Study of sugarcane bagasse pretreatment with sulfuric acid as a step of cellulose obtaining. WASET Int. J. Biol. Biomol. Agric. Food Biotechnol. Eng. 6, 6-10.

Rocha, J.R.A.S.C., Machado, J.C., Carneiro, P.C.S., Carneiro, L.C., Resende, M.D.V., Pereira, A.V., Carneiro, J.E.S., 2017. Elephant grass ecotypes for bioenergy production via direct combustion of biomass. Ind. Crops Prod. 95, 27-32.

Samson, R., Mani, S., Boddey, R., Sokhansanj, S., Quesada, D., Urquiaga, S., Reis, V., Holem, C., 2005. The potential of C4 perennial grasses for developing a global BIOHEAT industry. Crit. Rev. Plant Sci. 24, 461-495.

Sant'Anna, C., Costa, L.T., Abud, Y., Biancatto, L., Miguens, F.C., De Souza, W., 2013. Sugarcane cell wall structure and lignin distribution investigated by confocaland electron microscopy. Microsc. Res. Tech. 76, 829-834.

Sant'Anna, C., Souza, W., Brienzo, M., 2014. The influence of the heterogeneity, physicochemical and structural properties on the recalcitrance and conversion of sugarcane bagasse. Sugarcane, Production, Consumption and Agricultural Management Systems. Nova Science Publisehrs, Webb, E., New York.

Santos, E.A., da Silva, D.S., Queiroz Filho, J.L., 2001. Composição Química do CapimElefante cv. roxo cortado em diferentes alturas. Rev. Bras. Zootec. 30, 18-23.

Satyanarayana, K.G., Wypych, F., 2007. Characterization of natural fibers. Eng. Biopol.: Homopolym. Blends Compos. 1, 3-47.

Scholl, A.L., Menegol, D., Pitarelo, A.P., Fontana, R.C., Zandoná, F.A., Ramos, L.P., Camassola, M., 2015. Elephant grass (Pennisetum purpureum Schum.) pretreated via steam explosion as a carbon source for cellulases and xylanases in submerged cultivation. Ind. Crops Prod. 70, 280-291.

Sheng, C., Azevedo, J.L.T., 2005. Estimating the higher heating value of biomass fuels from basic analysis data. Biomass Bioenergy 28 (5), 499-507.

Sladden, S.E., Bransby, D.I., Aiken, G.E., Prine, G.M., 1991. Biomass yield and composition: and winter survival of tall grasses in Alabama. Biomass Bioenergy 1, 123-127.

Sluiter, A., Hames, B., Ruiz, R., Scarlata, C., Sluiter, J., Templeton, D., 2010. Compositional analysis of lignocellulosic feedstocks. Review and description of methods. J. Agric. Food Chem. 58, 9043-9053.

Wallace, J., Brienzo, M., Garcia-Aparicio, M., Görgens, J., 2016. Lignin enrichment and enzyme deactivation as the root cause of enzymatic hydrolysis slowdown of steam pretreated sugarcane bagasse. New Biotechnol. 33, 2016.

Wang, S., Wang, K., Liu, Q., Gu, Y., Luo, Z., Cen, K., Fransson, T., 2009. Comparison of the pyrolysis behavior of lignins from different tree species. Biotechnol. Adv. 27, 562-567.

Zeng, M., Ximenes, E., Ladisch, M.R., Mosier, N.S., Vermerris, W., Huang, C.-P., Sherman, D.M., 2012. Tissue-specific biomass recalcitrance in corn stover pretreated with liquid hot-water: enzymatic hydrolysis (Part 1). Biotechnol. Bioeng. 109, 390-397. 